\title{
Proposed Theory for Management of COVID_19: Thermal Shock to Viral wall Lipoprotein.
}

\author{
Yasser $\operatorname{Ali}^{1}$ \\ ${ }^{1}$ Al-Azhar University
}

June 15, 2020

\begin{abstract}
Proposed Theory for Management of COVID_19: Thermal Shock to Viral wall Lipoprotein. Abstract The global pandemic of COVID_19 is challenging the world, it pushes the health professional minds all over the world to think of a solution. Up to date there is shortage in the full information about the virus, however it is a viral RNA has lipoprotein membrane. Taking in consideration the available data and based on simple scientific facts, Author proposes a theory to be clinically investigated on a wide scale of COVID_19 infected Randomized control studies phase 2 without needing to animal studies as it depends on just hot vapor. This proposed thermal attack will eliminate a lot of viruses inside respiratory tract secretions. It literally means decreasing the COVID_19 Viruses load and allows body immune system to combat the virus with almost no or a little cytokine storm. It could decrease the spread of infection among contacts with cases infected with Corona viruses. This idea can simply quiet the morbidity and mortality curve. Keywords: COVID_19; Thermal; Destruction; Viral wall; Ventilator Setup.
\end{abstract}

\section{INTRODUCTION}

Corona Pandemic virus is challenging worldwide problem nowadays. This Article is to propose a protocol for its management based on simple scientific facts and on the collected information about COVID_19.

According to (WHO release 2020) facts about COVID_19, Corona virus; Heat at $56{ }^{\circ} \mathrm{C}$ kills the SARS Corona virus per 15 minutes at around 10000 units.

The lung tissue heat resistance and the alveolar thermal tolerance are not well known, but the thermal tolerance of the skin is ( Ali2018; Mark et al 2003) However the skin can't tolerate a degree of 56 for 15 minutes without burns and this of course the situation in alveolar tissue and may be less.

Reviewing of thermal tolerance of tissue heat response (Mark et al 2003 ) shows the importance of exposure time and tissue types. Evidently experimental and Clinical findings ${ }^{3}$ showed safety of gradual heating of tissue at rate ranging from 0.1 to $0.7^{\circ} \mathrm{C} / \mathrm{min}$., and hence tissue tolerance reaches $45-46^{\circ} \mathrm{C}$. The breakpoints of thermal cytotoxic starts at $47^{\circ} \mathrm{C}$ but skin exposure to $44^{\circ} \mathrm{C}\left(111^{\circ} \mathrm{F}\right)$ needs about 6 hours to cause burn injury. This could be mimic or slightly more for the Respiratory tract.

Moreover, statistical study (Bukhari et al 2020 ) supposes the attenuating effect of humidity and high temperature on Corona Virus COVID_19. Also long time ago in Vitro study ${ }^{5}$ on a species of Corona Virus demonstrated that; temperature $\left(38^{\circ} \mathrm{C}\right) 80-90 \%$ relative humidity results in $0.25 \log 10$ loss of titre at 24 hours.

\section{IDEA AND THEORY}

So the idea is how to attack the lipoprotein membrane of Corona virus for 24 hours in the airway of the infected person either in mild, moderate or severe cases who are on Ventilators. At the same time the thermal attack should be safe to the respiratory tissues. 
As the Virus inside respiratory tract is protected by inside secretions so we should calculate the actual required temperature essential to heat upper and lower airways' secretions to the degree that could cause Viral Coat destruction. This could decrease the extracellular viruses count and could decrease the overall viral load. (Francois 2020 ) Hence the fat density is 0.9 of water (Ali 2018) so if we could raise the temperature in respiratory tract secretion $1 \mathrm{C}$ this will deliver $1.333^{\circ} \mathrm{C}$ thermal injury to the lipoprotein coat of the virus. So the infected person with Corona needs to inhale $48.76[?] \quad 49{ }^{\circ} \mathrm{C}$ of continuous hot Vapor with [?] $90 \%$ humidity for 15 minutes! This is unsafe for the lungs. This degree is thermal cytotoxic for human lungs. This would be more than the thermal threshold for alveolar damage even if delivered in short time about 15 minutes. The question to be urgently investigated is why not deliver $38 \mathrm{degC}$ or more $-44 \mathrm{degC}$ or less (which safer to the lung) of humid Vapor into patient's airway? Author thinks this could be a great idea for the management of COVID_19.

This proposed thermal attack will eliminate a lot of extra-cellular viruses, inside respiratory tract secretions. It literally means decreasing the COVID_19 Viruses load (Francois 2020) and allows body immune system to combat the virus with almost no or a little cytokine storm. This idea can simply quiet the morbidity and mortality curve.

Although studies are not mentioning the viral count/each infected air droplet, this proposed heating approach, also may decrease the virulence of infection, when the viral count in the droplets are decreased with subsequent decrease in spread of infection to contacts.

These methods could be designed carefully for investigation by Heath providers who treating Victims with COVID_19 in different models of degree, duration and rate of lung tissue heating in randomized control study groups till complete recovery. This Idea could be also designed and delivered for patients on Ventilators according to each case clinical data. According to general data obtained from ICU specialized article, (Haitham 2014 ) physicians can keep the ventilation humidity at $100-120 \%$ and temperature at $40.7 \mathrm{C}=$ (55X0.74) if they adjusted the heater at 55 to compensate the tube loss $(0.74 \%)$. They could deliver different degrees of heating and humidity in the study.The article propose a theory of Safe heat thermolysis Attack of Corona virus COVID_19, to destruct its lipoprotein coat and that could make sense in the investigational studies.

Something to be mentioned; In Vitro studies (El Badrawy 2018; Maya 2018; Yonekura, 2020) recommended the Idea of Application of sodium bicarbonate (SB) in the heated humidified Vapor as an adjuvant to the kill the respiratory tract pathogens, via simple inhalation or even bronchoscopy or endotracheal tube may provide an additional help in management of COVID_19. Correction of Stress acidosis could not be neglected in patients with respiratory Failure. Parenteral SB will not affect the intracellular $\mathrm{PH}=7.2$ but will correct the blood PH when needed.

All health governments must now take decisive action to investigate every possible assumption to combated COVID_19 (Lancet ed. 2020 ; Lo, V.T., 2020)

Acknowledgment: To Mrs Nashwa Saleh for her help and support.

Conflict of interest statement: The Author has no any conflict of interest

Disclosure: The author has no financial interest to declare in relation to the content of this article.

Data availability is available on request

Ethical Statement is not applicable

\section{References}

1. First data on stability and resistance of SARS coronavirus compiled by members of WHO laboratory network. (2020). Available at https://www.who.int/csr/sars/survival_2003_05_04/en/

2. Ali, Y.H., Laser-assisted Lipolysis Burn Safety: (2018) Proposed Detailed Parameters with Assessment of Their Efficacy and Safety.Plast. Reconstr Surg. GO 1943; 
doi:10.1097/gox.00000000000001934;published on line 3 october 2018

3. Mark, W., Dewhirst, B. L. Viglianti, Michael Lora-Michiels, et al.( 2003) Thermal Dose Requirement For Tissue Effect: Experimental And Clinical Findings. Proc SPIE Int Soc Opt Eng. 2: 4954: 37 doi:10.1117/12.476637.

4. Bukhari, Q., and Jameel, Y., Will Coronavirus Pandemic Diminish by summer?

(2020). Available at SSRN: https://ssrn.com/abstract=3556998 or http://dx.doi.org/10.2139/ssrn.3556998

1. Chan, k., Malik. P., Lam S., et al. (2011) The effects of temperature and relative humidity on the viability of SARS Coronavirus. Advances in Virology . dio:10.1155/2011/734690.

2. Francois,X. L., Lila B., Duc N., et al. (2020) Clinical and virological data of the first cases of COVID-19 in Europe: a case series. Lancet Infect Dis 2020 Published Online March 27, https://doi.org/10.1016/ S1473-3099(20)30200-0

3. Haitham S., and Ariel M., (2014) Humidification during Mechanical Ventilation in the Adult Patient. BioMed Research International. avilable at: http://dx.doi.org/10.1155/2014/715434

4. El Badrawy, E.M., Yousef A., et al.( 2018) Effect of sodium bicarbonate $8.4 \%$ on respiratory tract pathogens. Chest Lung Res. 1:(1)

5. Maya, A., Shawn, Fr., Jonathan, M., et al.( 2018) Bicarbonate Alters Bacterial Susceptibility to Antibiotics by Targeting the Proton Motive Forc ACS Infectious Diseases. 4 (3), 382-390 DOI: 10.1021/acsinfecdis.7b00194

6. Yonekura, H., Kawasaki, Y., Nakamori, Y., et al.( 2020) The Use of Sodium Bicarbonate for Metabolic Acidosis in Patients with Acute Kidney Injury. Critical Care Medicine . 48: (3) - p e251-e252 doi: 10.1097/CCM.0000000000004111

7. Editorial, ( 2020) COVID-19: delay, mitigate, and communicate The Lancet Respiratory Medicine. 8 (4): P321, March 16, 2020DOI:https://doi.org/10.1016/S2213-2600(20)30128-4

8. Lo, V.T., Yoon, S.-W., Noh, J.Y., Kim, Y., Choi, Y.G., Jeong, D.G. and Kim, H.K. (2020), Long-term surveillance of bat coronaviruses in Korea: Diversity and distribution pattern. Transbound Emerg Dis. Accepted Author Manuscript. doi:10.1111/tbed.13653 